\title{
Zur Kenntnis der Alkalischmelze von Benzolsulfosäuren
}

\section{Doctoral Thesis}

Author(s):

Stamm, Guido

Publication date:

1940

Permanent link:

https://doi.org/10.3929/ethz-a-000099033

Rights / license:

In Copyright - Non-Commercial Use Permitted 


\section{Zur Kenntnis der Alkalischmelze von Benzolsulfosäuren}

\section{Von der \\ Eidgenössischen Technischen Hochschule in Zürich}

zur Erlangung der

Würde eines Doktors der technischen Wissenschaften

genehmigte

\section{Promotionsarbeit}

vorgelegt von

\section{Guido Stamm}

dipl. Ingenieur-Chemiker

ans Schleitheim (Schaffhausen)

Referent: Herr Prof. Dr. H. E. Fierz

Korreferent: Herr Prof. Dr. L. Ruzicka

AFFOLTERN AM ALBIS

BUCHDRUCKEREI DR. J. WEISS

1940 


\section{Zusammenfassung.}

Es wurde die Benzol-m-disulfosäure im Autoklaven mit wässeriger $\mathrm{NaOH}$ unter Zusatz von $\mathrm{Ca}(\mathrm{OH})_{2}$ unter Druck erhitzt und das Reaktionsprodukt untersucht. 'Ferner wurde dieselbe Säure' mit Aetznatron trocken im Vakuum gebackt und die Abhängigkeit der Resorcinausbeute von Temperatur und Alkaliüberschuß untersucht. Es wurde dabei festgestellt:

1. Aus der Druckschmelze konnten stets nur Spuren von Resorcin und Phenol erhalten werden. Bei $400^{\circ}$ wurden $46 \%$ der Disulfosäure zu $\mathrm{CO}_{2}$ oxydiert.

2. Die Alkalischmelze der Benzol-m-disulfosäure im Backapparat kann bis zu einer Temperatur von $350^{\circ}$ durchgeführt werden, wobei man bei $100 \%$ Alkaliüberschuß $80 \%$ Resorcin erhält.

Es wurden ferner die Benzol-p-disulfosäure, Phenol-p-sulfosäure und die Chlorbenzol-p-sulfosäure hergestellt und auf ihr Verhalten gegenüber geschmolzenem Alkali untersucht; im Anschluß daran wurde p-Chlorphenol im Autoklaven mit Aetznatron behandelt. Es wurde gefunden, daß

3. die Benzol-p-disulfosäure sich mit ca. $5 \%$ iger Ausbeute in Resorcin umlagern läßt.

4. die Phenol-p-sulfosäure im Gegensatz $\mathrm{zu}$ ihren Isomeren gegen Alkali sehr beständig ist und praktisch keine Dioxybenzole ergibt.

5. die p-Chlorbenzolsulfosäure ohne Katalysator schlecht in Resorcin umgelagert wird.

6. das p-Chlorphenol im Autoklaven bei $280^{\circ}$ mit Lauge erhitzt zum größten Teil Phenol und Dioxydiphenyle ergibt; es wurde daneben auch die Spaltung in Ameisensäure festgestellt. 